\title{
TESTES PARA AVALIAÇÃO DO VIGOR DE SEMENTES DE SORGO COM ENNFASE À CONDUTIVIDADE ELÉTRICA
}

\author{
Vigor tests in sorghum seeds with emphasis to electrical conductivity \\ Marcos Morais Soares ${ }^{1}$, Patrícia Marluci da Conceição ${ }^{1}$, \\ Denise Cunha Fernandes dos Santos Dias ${ }^{2}$, Eveline Mantovani Alvarenga ${ }^{3}$
}

\begin{abstract}
RESUMO
As pesquisas realizadas têm mostrado que o teste de germinação nem sempre revela diferenças de desempenho entre lotes de sementes, assim, tem-se estudado métodos que permitam diferenciar os lotes utilizando-se os testes de vigor. Assim, conduziu-se este trabalho, com o objetivo de estudar a eficiência de diferentes testes de vigor na avaliação da qualidade fisiológica de sementes de sorgo, cultivar CMSXS 222, bem como avaliar o efeito do volume de água e do período de embebição na sensibilidade do teste de condutividade elétrica. Foram conduzidos os testes de germinação, primeira contagem de germinação, imersão em solução de cloreto de amônio, envelhecimento acelerado, teste frio sem solo, emergência de plântulas em casa de vegetação e condutividade elétrica. A condutividade elétrica foi avaliada após $2,4,6,8,16,24$ e 48 horas de embebição, utilizando-se quatro subamostras de 50 sementes, imersas em 50 e $75 \mathrm{~mL}$ de água, a $25^{\circ} \mathrm{C}$. Os resultados mostraram que o teste de germinação detectou dois níveis de vigor, enquanto o teste de emergência em casa de vegetação detectou três níveis de vigor, mostrando que o teste de germinação apresenta algumas limitações no que se refere à diferenciação de lotes. Entre os testes de vigor realizados em laboratório, o teste de envelhecimento acelerado e teste de frio sem solo mostraram alta correlação significativa com o teste de emergência de plântulas em casa de vegetação. No teste de condutividade elétrica, somente o lote de qualidade inferior foi discriminado com 2, 4 e 6 horas de embebição em $75 \mathrm{~mL}$ de água, e com 16 horas de embebição em $50 \mathrm{~mL}$ de água. Conclui-se, com este trabalho, que o teste de envelhecimento acelerado e o teste frio sem solo foram eficientes em separar os lotes de sementes de sorgo em níveis de vigor se comparados ao teste de emergência de plântulas em casa de vegetação. O teste de condutividade elétrica não constitui opção eficiente para classificação dos lotes em níveis de vigor de sementes de sorgo, possibilitando identificar apenas lotes de baixo vigor.
\end{abstract}

Termos para indexação: Sorghum bicolor, Qualidade fisiológica, vigor.

\begin{abstract}
The researches show that germination tests do not always reveal differences between seed lots, so that other methods have been studied that allow to differentiate the lots using vigor tests. The goal of this research was, therefore, to verify the efficiency of different vigor tests on the evaluation the physiological quality of sorghum seeds and to determine the effects of water volume and imbibition period on the efficiency of the electrical conductivity test to evaluate sorghum seed vigor. The physiological quality of the seeds was evaluated by the germination test, first count, cold test without soil, immersion in ammonium chloride, seedling emergence in greenhouse and accelerated aging. Electrical conductivity was determined at 2, 4, 6, 8, 16, 24 and 48 hours imbibition, using four subsamples of 50 seeds, soaked in 50 and $75 \mathrm{~mL}$ water, at $25^{\circ} \mathrm{C}$. The results showed that the germination test detected two levels of vigor, while the seedling emergence in greenhouse detected three levels of vigor, showing that the germination test has some limitations regarding the differentiation of lots. Among vigor tests carried out in the laboratory, the test of accelerated aging and cold test without soil showed a highly significant correlation with seedling emergence in greenhouse. In the test of electric conductivity only the lot of inferior quality was discriminated with 2, 4 and 6 hours of imbibition in $75 \mathrm{~mL}$ of water, and with 16 hours of imbibition in $50 \mathrm{~mL}$ of water. It was concluded that the accelerated aging and cold test were efficient for vigor evaluation of sorghum seeds compared to the seedling emergence in greenhouse. The test of electric conductivity is not an efficient option for classification of the lots in levels of vigor of sorghum seeds, just identifying lots with low vigor.
\end{abstract}

Index terms: Sorghum bicolor, physiological quality, vigor.

(Recebido em 5 de julho de 2008 e aprovado em 16 de julho de 2009)

\section{INTRODUÇÃO}

O sorgo [Sorghum bicolor (L.) Moench], originário do centro da África e parte da Ásia, constitui-se atualmente numa importante alternativa para alimentação humana e animal, especialmente em regiões de baixa disponibilidade de água, por apresentar sementes ricas em proteínas, vitaminas, hidrato de carbono e sais minerais, além de produzir plantas com elevado volume de massa verde e que apresentam tolerância à seca e a alta temperatura (Carvalho et al., 2000).

\footnotetext{
1Universidade Federal de Viçosa/UFV - Viçosa, MG

2Universidade Federal de Viçosa/UFV - Departamento de Fitotecnia - Viçosa, MG - dcdias@ufv.br

3Universidade Federal de Viçosa/UFV - Departamento de Fitotecnia - Viçosa, MG
} 
O teste de germinação é o procedimento oficial para avaliar a capacidade das sementes produzirem plântulas normais em condições ideais, mas, nem sempre revela diferenças de desempenho entre lotes de sementes durante o armazenamento ou em campo (Carvalho \& Nakagawa, 2000). Para uma análise completa da qualidade de sementes, há necessidade de se complementar as informações fornecidas pelo teste de germinação utilizando-se testes de vigor, os quais possibilitam selecionar os melhores lotes para comercialização (Dias et al., 2006).

Os objetivos básicos dos testes de vigor são: avaliar ou detectar diferenças significativas na qualidade fisiológica de lotes com germinação semelhante; distinguir, com segurança, lotes de alto dos de baixo vigor; separar ou classificar lotes em diferentes níveis de vigor, de maneira proporcional ao comportamento quanto à emergência das plântulas em campo e ao potencial de armazenamento (Marcos Filho, 1999).

Dentre os testes de vigor considerados mais importantes encontram-se os testes de frio, envelhecimento acelerado e condutividade elétrica. Este último, além de possuir base teórica consistente, tem como características a objetividade, rapidez e facilidade de execução (Association of Official Seed Analysts-AOSA, 1983; International Seed Testing Association-ISTA, 1995).

A condutividade elétrica baseia-se no princípio de que com o avanço do processo de deterioração da sementes, há perda na integridade dos sistemas de membranas da célula, aumentando, assim, sua permeabilidade e, consequentemente, a lixiviação de eletrólitos. Dessa forma, o teste baseia-se na modificação da resistência elétrica, causada pela lixiviação de eletrólitos dos tecidos da semente para a água em que ficou imersa (Vieira \& Krzyzanowsky, 1999).

Nesse teste, a duração do período de embebição das sementes tem efeito decisivo na capacidade do teste distinguir diferenças de qualidade entre lotes (Dias et al., 2006). Algumas espécies apresentam liberação inicial de eletrólitos intensa, tanto pelas sementes intactas e vigorosas como pelas danificadas, torna-se difícil a identificação de possíveis diferenças de qualidade entre os lotes logo no início da embebição. Para estas espécies, com o decorrer desse processo, contudo, a quantidade de exsudatos liberados pelas sementes vigorosas vai se estabilizando, em razão principalmente, da reorganização das membranas (Rosa et al., 2000).

$\mathrm{O}$ teste de condutividade elétrica, tradicionalmente, tem sido conduzido com 24 horas de imersão das sementes em água, em sementes de ervilha e soja, por se tratar de um período adequado para a rotina normal dos laboratórios de análise de sementes (Dias \& Marcos Filho, 1996). No entanto, vários trabalhos têm indicado a possibilidade de utilização de períodos mais curtos como Dias et al. (1998) avaliando sementes de feijão-de-vagem e quiabo; Vanzolini \& Nakagawa (1999) que avaliaram sementes de amendoim e Dutra \& Vieira (2006) que avaliaram sementes de abobrinha. Torres et al. (1998) verificaram que é possível reduzir para quatro horas de embebição o período de condicionamento em sementes de maxixe, enquanto Gaspar \& Nakagawa (2002) afirmam que é possível reduzir para duas horas, em sementes de milheto. A possibilidade da redução desse período é vantajosa para a indústria de sementes, pois permite agilizar as tomadas de decisão referentes ao manejo dos lotes (Marcos Filho et al., 1990). Contudo, Marcos Filho et al. (1990) obtiveram distinção entre lotes de sementes de soja, quando a diferença de vigor era grande, com o uso de 4 ou 8 horas de embebição; entretanto, quando a diferença entre os lotes era pequena, o período de embebição por 16 ou 20 horas mostrou-se mais sensível às variações do vigor das sementes de soja. Resultados semelhantes foram obtidos por Dias \& Marcos Filho (1996).

Além do período de embebição, Vieira \& Krzyzanowsky (1999) afirmam que o volume de água pode afetar os resultados do teste. No entanto, Dias et al. (2006) não observaram efeito do volume de água $(25$ e $50 \mathrm{~mL})$ na estratificação em níveis de vigor de lotes de sementes de cebola. Dutra \& Vieira (2006) observaram redução dos valores de condutividade elétrica obtidos com $75 \mathrm{~mL}$ de água em comparação aos obtidos com $50 \mathrm{~mL}$, o que está relacionado ao efeito de diluição dos lixiviados.

Objetivou-se, no presente trabalho, estudar a eficiência de diferentes testes de vigor na avaliação da qualidade fisiológica de sementes de sorgo, bem como avaliar o efeito do volume de água e do período de condicionamento das sementes nos resultados do teste de condutividade elétrica.

\section{MATERIAL E MÉTODOS}

A pesquisa foi desenvolvida no Laboratório de Sementes e em Casa de Vegetação pertencentes ao Departamento de Fitotecnia da Universidade Federal de Viçosa, MG. Utilizaram-se cinco lotes de sementes de sorgo [Sorghum bicolor (L.) Moench cv. CMSXS 222], que foram submetidos aos seguintes testes e determinações:

Teor de água - determinado pelo método da estufa, a $105 \pm 3^{\circ} \mathrm{C}$, durante 24 horas (Brasil, 1992), com duas repetições de aproximadamente $3,0 \mathrm{~g}$. Os resultados foram expressos em porcentagem (base úmida). 
Germinação - conduzido com quatro repetições de 50 sementes. Utilizou-se como substrato rolo de papel germitest umedecido com volume de água equivalente a 2,5 vezes o peso do substrato seco. Após a semeadura, os rolos foram mantidos em germinador a $25^{\circ} \mathrm{C}$. As avaliações foram feitas no $4^{\circ}$ e $10^{\circ}$ dia após a semeadura, com o registro da porcentagem de plântulas normais (Brasil, 1992),

Primeira contagem da germinação - consistiu do registro da porcentagem de plântulas normais obtidas no quarto dia após a instalação do teste de germinação.

Imersão em solução de cloreto de amônio - seguiu-se a metodologia descrita por Marcos Filho et al. (1987) com modificações. Foram utilizadas quatro repetições de 50 sementes, imersas em solução de cloreto de amônio $2 \%$, permanecendo em incubadora BOD, a $40^{\circ} \mathrm{C}$, por duas horas; a seguir, as sementes foram lavadas em água corrente e colocadas para germinar, conforme descrito para o teste de germinação; no sexto dia, avaliou-se a porcentagem de plântulas normais.

Envelhecimento acelerado - as sementes foram distribuídas em camada única sobre a superfície de uma bandeja com tela de alumínio, que foi acoplada ao interior de uma caixa plástica de germinação $(11 \times 11$ x 3,5 cm), contendo, ao fundo, $40 \mathrm{~mL}$ de água. As caixas foram tampadas e mantidas a $41^{\circ} \mathrm{C}$, em BOD, por 96 horas (Marcos Filho, 1994). Decorrido esse tempo, quatro repetições de 50 sementes foram submetidas ao teste germinação, conforme descrito acima (Brasil, 1992). No quinto dia, foi registrada a porcentagem de plântulas normais.

Teste frio sem solo - conduzido com quatro repetições de 50 sementes distribuídas em papel germitest, conforme descrito para o teste de germinação. Os rolos foram colocados em sacos plásticos e permaneceram em incubadora BOD, a temperatura constante de $10^{\circ} \mathrm{C}$, durante sete dias. Após esse período, foram transferidos para germinador a $25^{\circ} \mathrm{C}$, onde permaneceram por sete dias. Os resultados foram expressos em porcentagem de plântulas normais (Barros et al., 1999).

Emergência de plântulas em casa de vegetação - conduzido em bandejas plásticas contendo areia e solo (1:1). Foram utilizadas quatro repetições de 40 sementes por lote, distribuídas em sulcos com $1 \mathrm{~cm}$ de profundidade e distantes $2 \mathrm{~cm}$ entre si. O substrato foi umedecido sempre que necessário e a avaliação final das plântulas foi realizada aos 15 dias após a semeadura (Nakagawa, 1994).

Condutividade elétrica (CE) - foi empregado o método de massa (AOSA, 1983), utilizando-se quatro repetições de 50 sementes, previamente pesadas, imersas em 50 ou $75 \mathrm{~mL}$ de água destilada, permanecendo em incubadora BOD, a $25^{\circ} \mathrm{C}$, por 2, 4, 6, 8, 16, 24 e 48 horas. Após cada período, realizouse a leitura da condutividade elétrica em condutivímetro, sendo os resultados expressos em $\mu \mathrm{S} \mathrm{cm}^{-1} \mathrm{~g}^{-1}$ de semente.

Utilizou-se o delineamento experimental inteiramente casualizado, com quatro repetições. As médias foram comparadas pelo teste de Tukey a 5\% de probabilidade. Foram calculados ainda os coeficientes de correlação simples (r) entre os resultados dos testes de vigor e os de emergência de plântulas em casa de vegetação; a significância dos valores de $\mathrm{r}$ foi determinada pelo teste $\mathrm{t}$, a 5 e $1 \%$ de probabilidade.

\section{RESULTADOS E DISCUSSÃO}

Na Tabela 1, é apresentada a caracterização da qualidade inicial das sementes dos diferentes lotes. $\mathrm{O}$ teor de água das sementes foi semelhante para os cinco lotes estudados, com variação máxima de 0,7 pontos percentuais. Esse fato é importante na execução dos testes de vigor, considerando-se que a uniformização do teor de água das sementes é imprescindível para a padronização das avaliações e obtenção de resultados consistentes (Marcos Filho et al., 1987).

Tabela 1 - Caracterização da qualidade de cinco lotes de sementes de sorgo, cv. CMSXS 222, pelo teor de água (TA), germinação (GERM), primeira contagem de germinação (PC), imersão em solução de cloreto de amônio (ICA), envelhecimento acelerado (EA), teste frio sem solo (TF), emergência de plântulas em casa de vegetação (EMERG).

\begin{tabular}{|c|c|c|c|c|c|c|c|}
\hline Lotes & TA & GERM & $\mathrm{PC}$ & ICA & EA & $\mathrm{TF}$ & EMERG \\
\hline \multicolumn{8}{|c|}{ 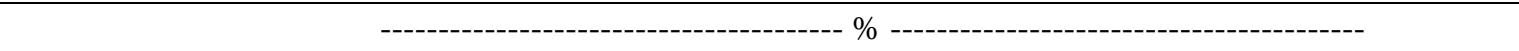 } \\
\hline 1 & 14.4 & $74 \mathrm{~b}$ & $53 \mathrm{c}$ & $69 \mathrm{c}$ & $57 \mathrm{~b}$ & $70 \mathrm{~b}$ & $80 \mathrm{~b}$ \\
\hline 2 & 13.8 & $90 \mathrm{a}$ & $77 \mathrm{ab}$ & $74 \mathrm{bc}$ & $58 \mathrm{~b}$ & $69 \mathrm{~b}$ & $79 \mathrm{~b}$ \\
\hline 3 & 14.2 & $76 \mathrm{~b}$ & $62 \mathrm{bc}$ & $68 \mathrm{c}$ & $33 \mathrm{c}$ & $44 \mathrm{c}$ & $65 c$ \\
\hline 4 & 13.6 & $95 \mathrm{a}$ & $82 \mathrm{a}$ & $91 \mathrm{a}$ & $73 \mathrm{a}$ & $88 \mathrm{a}$ & $92 \mathrm{a}$ \\
\hline 5 & 14.2 & $91 \mathrm{a}$ & 78 a & $86 \mathrm{ab}$ & $54 \mathrm{~b}$ & $77 \mathrm{~b}$ & $82 \mathrm{~b}$ \\
\hline CV (\%) & & 5,75 & 9,96 & 7,59 & 11,66 & 6,10 & 4,97 \\
\hline
\end{tabular}

Médias seguidas da mesma letra, em cada coluna, não diferem pelo teste de Tukey a $5 \%$ de probabilidade. 
Pelo teste de germinação (Tabela 1), observa-se que os lotes 2, 4 e 5 tiveram desempenho superior aos lotes $1 \mathrm{e}$ 3. Segundo Dias et al. (1998), a avaliação da viabilidade das sementes é feita, para fins de comercialização, basicamente pelo teste de germinação, no entanto, esse teste apresenta algumas limitações, principalmente no que se refere à diferenciação de lotes.

Pelo teste de emergência em casa de vegetação, entretanto, detectou-se três níveis de vigor. Marcos-Filho et al. (1990) verificando discrepâncias entre os testes de germinação e de vigor, comentaram que estas não constituem ocorrências incomuns em trabalhos de pesquisa, pois, esses testes avaliam diferentes aspectos do comportamento das sementes.

Os lotes 1 e 3 não diferiram na porcentagem de germinação, assim, apesar de esses lotes apresentarem um padrão mínimo de germinação inferior ao recomendado para a comercialização de sementes de sorgo (Tabela 1), que está estabelecida em 80\% (Brasil, 2008), foram avaliados nos testes de vigor, pois, neste trabalho, objetivou-se avaliar diferentes testes de vigor que classifiquem os lotes com padrão semelhante de germinação. Nos testes de envelhecimento acelerado, teste de frio sem solo e emergência de plântulas em casa de vegetação foi possível verificar diferenças entre estes lotes (Tabela 1).

Pelo teste de germinação, pode-se verificar, de forma geral, maior porcentagem de plântulas normais que o teste de emergência em condições de casa de vegetação, com exceção do lote 1 (Tabela 1). Isso pode estar relacionado à maior disponibilidade de água, temperatura ideal e luminosidade no germinador, durante o teste de germinação, garantindo maior número de plântulas normais. Esses dados estão de acordo com Caliari \& Marcos Filho (1990), que afirmam que, se as condições de ambiente após a semeadura em campo se desviarem das ideais, é de se esperar que a porcentagem de emergência de plântulas seja inferior à germinação determinada em laboratório.

Entre os testes de vigor realizados em laboratório para as sementes de sorgo, os lotes foram efetivamente separados em níveis de vigor no teste de envelhecimento acelerado e teste de frio sem solo (Tabela 1), mostrando também alta correlação significativa (Tabela 2) com o teste de emergência de plântulas em casa de vegetação.

Os lotes 2 e 5 apesar de apresentarem germinação superior ao lote 1 (Tabela 1), os três lotes não diferiram nos testes de vigor, isso pode ser atribuído à queda do vigor que precede à perda da germinação. Assim, os lotes 2 e 5, apesar de apresentarem alta germinação, demonstram perda da qualidade fisiológica.

Os testes de primeira contagem de germinação e imersão em solução de cloreto de amônio, apesar de apresentarem correlação significativa (Tabela 2) com o teste de emergência de plântulas em casa de vegetação, não separaram de maneira efetiva os lotes de sementes em níveis de vigor (Tabela 1), pois, esses testes não classificaram os lotes de maneira semelhante ao teste de emergência.

Para ser avaliado como eficiente, um teste de vigor deve proporcionar uma classificação dos lotes em diferentes níveis de vigor, de maneira proporcional à da emergência das plântulas (Marcos-Filho, 1999). Portanto, verificou-se que a eficiência para distinguir os lotes de alto e baixo vigor foi mais destacada nos testes de envelhecimento acelerado e o teste frio sem solo.

Pelo teste de condutividade elétrica, utilizandose $75 \mathrm{~mL}$ de água (Tabela 3), observou-se que houve tendência de aumento na quantidade de eletrólitos liberados pelas sementes de sorgo, com o decorrer do tempo de embebição.

Verificou-se que nos períodos de duas, quatro e seis horas de embebição no teste de condutividade elétrica, em $75 \mathrm{~mL}$ de água, foi possível detectar o lote 3 como de qualidade inferior, não sendo possível detectar os lotes de qualidade superior e intermediária (Tabela 3). É importante ressaltar que, pelos resultados obtidos nos testes de envelhecimento acelerado, teste frio sem solo, emergência de plântulas em casa de vegetação, o lote 3

Tabela 2 - Coeficientes de correlação simples (r) entre os resultados do teste de emergência de plântulas em casa de vegetação e dos testes de germinação (GERM), primeira contagem de germinação (PC), imersão em solução de cloreto de amônio (ICA), envelhecimento acelerado (EA), teste frio sem solo (TF), determinados pelo teste t, a 5 e $1 \%$ de probabilidade $(\operatorname{Pr})$.

\begin{tabular}{cccccc}
\hline Testes & GERM & PC & ICA & EA & TF \\
\hline $\mathrm{r}$ & 0,60 & 0,46 & 0,69 & 0,80 & 0,91 \\
$\operatorname{Pr}$ & $* *$ & $*$ & $* *$ & $* *$ & $* *$ \\
\hline
\end{tabular}

(*) Significativo a $5 \%$ de probabilidade; $(* *)$ Significativo a $1 \%$ de probabilidade. 
também mostrou qualidade inferior aos demais. Tal resultado indica que, em $75 \mathrm{~mL}$ de água, o teste de condutividade elétrica não classificou os lotes em níveis de vigor, possibilitando identificar apenas lotes de baixo vigor. Assim, há a possibilidade de se utilizar tais resultados somente para o descarte de lotes de qualidade inferior. No entanto, Ribeiro et al. (1997), trabalhando com sementes de milho, verificaram que com o período de 12 horas foi possível detectar diferenças na qualidade fisiológica dos lotes de sementes. Gaspar \& Nakagawa (2002) afirmam que quanto maior foi o período de embebição maior o valor da condutividade, no entanto, esses autores observaram que nas duas horas iniciais ocorre uma taxa de lixiviação que possibilita a avaliação da condutividade elétrica da solução de embebição das sementes de milheto e de diferenciação dos lotes. Segundo Vieira \& Krzyzanowski (1999), em sementes pequenas é possível reduzir o período de embebição para o teste de condutividade elétrica.

Após seis horas de embebição, em $75 \mathrm{~mL}$ de água, não foi possível detectar o lote 3 como de qualidade inferior, como mostraram os resultados obtidos nos testes de envelhecimento acelerado, teste frio sem solo, emergência de plântulas em casa de vegetação (Tabela 3). Portanto, estes períodos não forneceram informações consistentes sobre o potencial de desempenho dos lotes, quando comparados aos resultados dos demais testes de vigor (Tabela 1).

Vale ressaltar que a embebição das sementes em água obedece a um padrão trifásico (Bewley \& Black, 1985) e que, principalmente, no início do processo de embebição, ocorre uma rápida e intensa liberação de eletrólitos até atingir um ponto de equilíbrio, quando as membranas celulares se reorganizam; isto pode dar suporte para a busca de informações sobre a qualidade fisiológica das sementes durante as fases iniciais de embebição (Dias \& Marcos Filho, 1996).

A redução do volume de água de 75 para $50 \mathrm{~mL}$ estabeleceu relação direta com o aumento do valor da condutividade na solução de embebição. O valor da condutividade, no menor volume de água, foi superior aos tratamentos com maior volume, indicando maior concentração de lixiviados no menor volume de água de embebição (Tabelas 3 e 4), o que também já havia sido constatado em outros trabalhos (Dias \& Marcos Filho, 1996; Dias et al., 2006; Dutra \& Vieira, 2006).

A evolução dos valores de condutividade elétrica, em $50 \mathrm{~mL}$ de água, para os cinco lotes foi semelhante até oito horas de embebição, não possibilitando a discriminação dos mesmos. Com 16 horas de embebição, foi possível verificar que o lote 3 apresentou qualidade inferior aos demais lotes (Tabela 3), o que já havia sido detectado após 2, 4 e 6 horas de embebição em $75 \mathrm{~mL}$ de água (Tabela 4). Com 24 e 48 horas não foi possível separar os lotes em níveis de vigor, quando se utilizou o volume de água de 50 $\mathrm{mL}$ (Tabela 4).

Verificou-se, no presente trabalho, que o teste de condutividade elétrica não foi eficiente para estratificar os lotes de sementes de sorgo em níveis de vigor, uma vez que só foi possível identificar o lote de qualidade inferior. Portanto, para a utilização do referido teste em programas de controle de qualidade há necessidade de estudos adicionais, buscando adequar a metodologia para as sementes dessa espécie.

Tabela 3 - Condutividade elétrica $\left(\mu \mathrm{S} . \mathrm{cm}^{-1} \cdot \mathrm{g}^{-1}\right)$ de sementes de cinco lotes de sorgo, cv. CMSXS 222, imersas em $75 \mathrm{~mL}$ de água, a $25^{\circ} \mathrm{C}$, após diferentes períodos de embebição.

\begin{tabular}{ccccccccc}
\hline & \multicolumn{10}{c}{ Períodos de embebição (h) } \\
\cline { 2 - 9 } Lotes & 2 & 4 & 6 & 8 & 16 & 24 ns $^{\text {ns }}$ & 48 \\
\hline & $11,9 \mathrm{c}$ & $16,3 \mathrm{~b}$ & $20,3 \mathrm{~b}$ & $23,4 \mathrm{~b}$ & $32,3 \mathrm{~b}$ & 36,4 & $45,1 \mathrm{ab}$ \\
2 & $20,3 \mathrm{~b}$ & $23,7 \mathrm{~b}$ & $26,2 \mathrm{~b}$ & $28,2 \mathrm{ab}$ & $33,0 \mathrm{ab}$ & 35,0 & $39,0 \mathrm{~b}$ \\
3 & $27,8 \mathrm{a}$ & $31,8 \mathrm{a}$ & $34,6 \mathrm{a}$ & $36,8 \mathrm{a}$ & $40,6 \mathrm{a}$ & 44,9 & $54,9 \mathrm{a}$ \\
4 & $18,0 \mathrm{bc}$ & $22,3 \mathrm{~b}$ & $25,4 \mathrm{~b}$ & $28,4 \mathrm{ab}$ & $31,6 \mathrm{~b}$ & 39,9 & $43,9 \mathrm{ab}$ \\
5 & $17,9 \mathrm{bc}$ & $21,2 \mathrm{~b}$ & $23,8 \mathrm{~b}$ & $26,0 \mathrm{~b}$ & $26,5 \mathrm{~b}$ & 34,7 & $38,9 \mathrm{~b}$ \\
\hline $\mathrm{CV}(\%)$ & 8,74 & 8,21 & 7,25 & 7,90 & 5,94 & 8,35 & 7,05 \\
\hline
\end{tabular}

Médias seguidas da mesma letra, em cada coluna, não diferem pelo teste de Tukey a 5\% de probabilidade. ( ${ }^{\text {ns }}$ ) não significativo pelo teste $\mathrm{F}$, a $5 \%$ de probabilidade. 
Tabela 4 - Condutividade elétrica de sementes de cinco lotes de sorgo, cv. CMSXS 222, imersas em 50 mL de água, a $25^{\circ} \mathrm{C}$, após diferentes períodos de embebição.

\begin{tabular}{cccccccc}
\hline & \multicolumn{10}{c}{ Períodos de embebição (h) } \\
\cline { 2 - 9 } Lotes & 2 & 4 & 6 & 8 & 16 & $24^{\text {ns }}$ & $48^{\text {ns }}$ \\
\hline & $18,5 \mathrm{~b}$ & $23,8 \mathrm{~b}$ & $27,7 \mathrm{~b}$ & $32,5 \mathrm{~b}$ & $40,1 \mathrm{c}$ & 52,9 & 61,1 \\
1 & $30,1 \mathrm{ab}$ & $34,4 \mathrm{ab}$ & $37,9 \mathrm{ab}$ & $41,2 \mathrm{ab}$ & $47,8 \mathrm{bc}$ & 55,6 & 58,7 \\
2 & $44,2 \mathrm{a}$ & $49,1 \mathrm{a}$ & $52,0 \mathrm{a}$ & $55,9 \mathrm{a}$ & $66,5 \mathrm{a}$ & 74,3 & 80,9 \\
3 & $31,1 \mathrm{ab}$ & $35,3 \mathrm{ab}$ & $37,7 \mathrm{ab}$ & $42,9 \mathrm{ab}$ & $53,6 \mathrm{~b}$ & 54,7 & 59,4 \\
4 & $25,5 \mathrm{~b}$ & $29,8 \mathrm{ab}$ & $33,0 \mathrm{ab}$ & $36,8 \mathrm{~b}$ & $44,1 \mathrm{bc}$ & 48,5 & 53,3 \\
\hline $\mathrm{CV}(\%)$ & 14,74 & 14,34 & 14,07 & 11,33 & 6,06 & 12,08 & 11,29 \\
\hline
\end{tabular}

Médias seguidas da mesma letra, em cada coluna, não diferem pelo teste de Tukey a 5\% de probabilidade. $\left({ }^{\mathrm{ns}}\right.$ ) não significativo pelo teste $\mathrm{F}$, a $5 \%$ de probabilidade.

\section{CONCLUSÕES}

O teste de envelhecimento acelerado e o teste frio sem solo foram eficientes em separar os lotes de sementes de sorgo em níveis de vigor se comparados com a emergência de plântulas em casa de vegetação.

O teste de condutividade elétrica não constitui opção eficiente para classificação dos lotes em níveis de vigor de sementes de sorgo, possibilitando identificar apenas lotes de baixo vigor.

\section{REFERÊNCIAS BIBLIOGRÁFICAS}

ASSOCIATION OF OFFICIAL SEED ANALYSTS. Seed vigour testing handbook. East Lasing, 1983. 88p. (Contribution, 32).

BARROS, A.S.R.; DIAS, M.C.L.L.; CÍCERO, S.M.; KRZYZANOWSKI, F.C. Teste frio. In: KRZYZANOWSKI, F.C.; VIEIRA, R.D.; FRANÇANETO, J.B.F. (Ed.). Vigor de sementes: conceitos e testes. Londrina: Abrates, 1999, p.5.1-5.15.

BEWLEY, J.D.; BLACK, M. Seeds: physiology of development and germination. New York: Plenum, 1985. $367 \mathrm{p}$.

BRASIL. Ministério da Agricultura e da Reforma Agrária. Regras para análise de sementes. Brasília: SNDA/ DNDV/CLAV, 1992. 365p.

BRASIL. Ministério da agricultura, pecuária e do abastecimento. Padrões para produção e comercialização de sementes de sorgo granífero e sorgo forrageiro cultivares não híbridas: variedades.
Disponível em: <http://extranet.agricultura.gov.br>l. Acesso em: 2 out. 2008.

CALIARI, M.F.; MARCOS FILHO, J. Comparação entre métodos para avaliação da qualidade fisiológica de sementes de ervilha (Pisum sativum L.). Revista Brasileira de Sementes, Brasília, v.12, n.3, p.52-75, 1990.

CARVALHO, L.F.; MEDEIROS-FILHO, S.; ROSSETTI, A.G.; TEÓFILO, E.M. Condicionamento osmótico em sementes de sorgo. Revista Brasileira de Sementes, Brasília, v.22, n.1, p.185-192, 2000.

CARVALHO, N.M.; NAKAGAWA, J. Sementes: ciência, tecnologia e produção. 4.ed. Jaboticabal: Funep, 2000. $424 \mathrm{p}$.

DIAS, D.C.F.S.; BHERING, M.C.; TOKUHISA, D.; HILST, P.C. Teste de condutividade elétrica para avaliação do vigor de sementes de cebola. Revista Brasileira de Sementes, Brasília, v.28, n.1, p.154-162, 2006.

DIAS, D.C.F.S.; MARCOS-FILHO, J. Testes de condutividade elétrica para avaliação do vigor de sementes de soja (Glycine max (L.) Merril). Scientia Agrícola, Piracicaba, v.53, n.1, p.31-42, 1996.

DIAS, D.C.F.S.; VIEIRA, A.N.; BHÉRING, M.C. Condutividade elétrica e lixiviação de potássio para avaliação do vigor de sementes de hortaliças feijão-devagem e quiabo. Revista Brasileira de Sementes, Brasília, v.20, n.2, p.170-175, 1998. 
DUTRA, A.S.; VIEIRA, R.D. Teste de condutividade elétrica para a avaliação do vigor de sementes de abobrinha. Revista Brasileira de Sementes, Brasília, v.28, n.2, p.117-122, 2006.

GASPAR, C.M.; NAKAGAWA, J. Teste de condutividade elétrica em função do período e da temperatura de embebição para sementes de milheto.

Revista Brasileira de Sementes, Brasília, v.24, n.2, p.8289, 2002.

\section{INTERNACIONAL SEED TESTING ASSOCIATION.} Handbook of vigour test methods. Zürich, 1995. 117p.

MARCOS FILHO, J. Teste de envelhecimento acelerado. In: VIEIRA, R.D.; CARVALHO, N.M. (Eds.). Testes de vigor em sementes. Jaboticabal: Funep, 1994. p.133-149.

MARCOS-FILHO, J. Testes de vigor: importância e utilização. In: KRZYZANOWSKI, F.C.; VIEIRA, R.D.; FRANÇA-NETO, J.B.F. (Eds.). Vigor de sementes: conceitos e testes. Londrina: Abrates, 1999. p.1.1-1.21.

MARCOS-FILHO, J.; CICERO, S.M.; SILVA, W.R. Avaliação da qualidade das sementes. Piracicaba: Fealq, 1987. 230p.

MARCOS FILHO, J.; SILVA, W.R.; NOVEMBRE, A.C.; CHAMA, H.C.P.C. Estudo comparativo de métodos para avaliação da qualidade fisiológica de sementes de soja, com ênfase ao teste de condutividade elétrica. Pesquisa Agropecuária Brasileira, Brasília, v.25, n.12, p.18051815,1990
NAKAGAWA, J. Testes de vigor baseados na avaliação das plântulas. In: VIEIRA, R.D.; CARVALHO, N.M. (Eds.). Testes de vigor em sementes. Jaboticabal: Funep, 1994. p.48-85.

RIBEIRO, D.M.C.A. Adequação do teste de condutividade elétrica da massa e individual para avaliação da qualidade fisiológica de sementes de milho (Zea mays L.). 1999. 116f. Dissertação (Doutorado em Fitotecnia)Universidade Federal de Lavras, Lavras, 1999.

ROSA, S.D.V.F.; PINHO, E.V.R.V.; VIEIRA, M.G.G.C.; VEIGA, R.D. Eficácia do teste de condutividade elétrica para uso em estudos de danos de secagem em sementes de milho. Revista Brasileira de Sementes, Brasília, v.22, n.1, p.54-63, 2000.

TORRES, S.B.; CASEIRO, R.F.; RODO, A.B.; MARCOS FILHO, J. Testes de vigor em sementes de maxixe (Cucumis Anguria L.) com ênfase ao teste de condutividade elétrica. Revista Brasileira de Sementes, Brasília, v.20, n.2, p.480-483, 1998.

VANZOLINI, S.; NAKAGAWA, J. Teste de condutividade elétrica em sementes de amendoim, efeitos de teor de água inicial e de período de embebição. Revista Brasileira de Sementes, Brasília, v.21, n.1, p.46-52, 1999.

VIEIRA, R.D.; KRZYZANOWSKI, F.C. Teste de condutividade elétrica. In: KRZYZANOWSKI, F.C.; VIEIRA, R.D.; FRANÇA NETO, J.B. (Eds.). Vigor de sementes: conceitos e testes. Brasília: Abrates, 1999. cap.4, p.1-26. 